\title{
ӘTropical North Atlantic Response to ENSO: Sensitivity to Model Spatial Resolution $\mathscr{O}$
}

\author{
JORGE LÓPEZ-PARAGES ${ }^{\mathrm{a}}$ AND LAURENT TERRAY ${ }^{\mathrm{a}}$ \\ ${ }^{a}$ CECI, Université de Toulouse, CERFACS/CNRS, Toulouse, France
}

(Manuscript received 29 March 2021, in final form 30 July 2021)

\begin{abstract}
In this study, the ENSO teleconnection with the tropical North Atlantic (TNA) sea surface temperatures (SSTs) in boreal spring is analyzed in ocean-atmosphere coupled global circulation models. To assess the role played by horizontal resolution of models on this teleconnection, we used a multimodel dataset that is the first to combine models with both low and high resolution. The TNA response to ENSO projects onto the most significant SST mode of the tropical Atlantic at interannual time scales, the Atlantic meridional mode (AMM). Its evolution is primarily driven by the windevaporation-SST (WES) feedback, which in turn is based on the development of an initial SST gradient. This study examines and quantifies the relative contribution of a dynamic-related (upwelling) and a thermodynamic-related (evaporation) process in triggering this gradient in the case of the ENSO-TNA teleconnection. While no major contribution is found with the evaporation, a consistent contribution from the coastal upwelling off northwest Africa is identified. This contribution is enhanced in high-resolution models and highlights the close link between the upwelling in winter and the development of the AMM in spring. It is further shown that high-resolution models present a thinner and more realistic ocean mixed layer within the upwelling area, which enhances the effect of surface winds on upwelling and SSTs. As a consequence, high-resolution models are more sensitive than low-resolution models to surface wind errors, thereby they do not ensure improved reliability or predictability of the TNA SST response to ENSO.
\end{abstract}

SIGNIFICANCE STATEMENT: Although the ENSO teleconnection with the tropical North Atlantic (TNA) sea surface temperatures (SSTs) is one of the most robust ENSO teleconnections, the processes behind the genesis of the initial SST anomalies over the eastern TNA are not completely understood. This study points to the coastal upwelling off northwest Africa as a major contribution of these initial ENSO-related SST anomalies. This role of the upwelling is, however, reproduced differently in ocean-atmosphere coupled models with different spatial resolutions. As a consequence, the choice of a model significantly affects the scope and predictability of the ENSO impact on the TNA. This novel result should be taken into account in future analyses before making categorical statements regarding this teleconnection.

KEYWORDS: Atmosphere-ocean interaction; ENSO; Teleconnections; Upwelling/downwelling; Oceanic mixed layer; Coupled models; General circulation models; Tropical variability

\section{Introduction}

Together with the Atlantic Niño (Zebiak 1993), the Atlantic meridional mode (AMM; Chiang and Vimont 2004) constitutes the most significant sea surface temperature (SST) mode of the tropical Atlantic at interannual time scales. AMM involves marked SST anomalies over the tropical North Atlantic (TNA) that generate an interhemispheric SST gradient with anomalous winds blowing to the warmer hemisphere (Nobre

๖ Denotes content that is immediately available upon publication as open access.

Supplemental information related to this paper is available at the Journals Online website: https://doi.org/10.1175/JCLI-D-210240.s1.

López-Parages's current affiliation: Physical Oceanography Group, University of Málaga, Málaga, Spain.

Corresponding author: Jorge López-Parages, parages@uma.es and Shukla 1996). As a consequence, the seasonal evolution of the intertropical convergence zone (ITCZ) is modified, with documented impacts on Atlantic hurricane activity (Vimont and Kossin 2007) and rainfall regime over the neighboring regions (Hastenrath and Heller 1977; Folland et al. 1986; Xie and Carton 2004).

The AMM peaks in boreal spring season and has been traditionally linked to the wind-evaporation-SST (WES) feedback (Xie and Philander 1994). According to this, cross-equatorial atmospheric flow related to the shift of the ITCZ reduces the strength of the trade winds in the warmer hemisphere and increases the strength of the trades in the cooler hemisphere. As a result, the evaporation and the latent heat loss are suppressed (intensified) in the warmer (cooler) hemisphere, which in turn reinforce the initial SST gradient. This theory is nowadays considered as the mechanism behind the evolution of the AMM mode. However, the WES feedback requires the existence of an initial SST gradient. The genesis of these initial SST anomalies in the case of the AMM has been traditionally related to trade wind variations and their effect on TNA SSTs through surface latent heat flux anomalies (Nobre and Shukla 1996). Nevertheless, other mechanisms might come into play. For example, those related to the Canary Upwelling 
System, which is located off the northwest African coast and constitutes one of the four main eastern boundary upwelling systems across the globe. The upwelling-favorable winds within this coastal upwelling system are related, as with AMM, to the fluctuation of the ITCZ. Furthermore, at interannual time scales both NAO and ENSO have been documented as common drivers for AMM (Czaja et al. 2002; Chiang and Vimont 2004; Taschetto et al. 2020) and northwest African upwelling (Roy and Reason 2001; Grossmann and Klotzbach 2009; Oettli et al. 2016). Paradoxically, the potential link between the Canary Upwelling System and the AMM has received much less attention.

Regarding ENSO, one of its most robust remote impacts is that affecting the TNA SSTs in boreal spring. This teleconnection is sustained by different mechanisms including: 1) Rossby wave trains propagation (Enfield and Mayer 1997), 2) changes in the zonal (Walker) and meridional (Hadley) cells (Wang 2004), and 3) a secondary Gill-type structure in the tropical Atlantic (García-Serrano et al. 2017). All these studies involve perturbations of the TNA trade winds from February to April and most of them focused on the role played by the ENSO influence on the latent heat flux anomalies linked to anomalous evaporation.

As mentioned, these anomalous trade winds can also alter the coastal upwelling off northwest Africa. However, the role played by the ENSO signature on the Canary Upwelling System (Roy and Reason 2001) for the subsequent development of SST anomalies along the TNA (i.e., the AMM-like pattern) remains largely unknown.

This seems to be partially explained by the fact that the spatial resolution of standard global circulation models hardly captures the ENSO influence on coastal upwelling. The present study attempts to fill this gap by using the first set of coordinated simulations made with both low- and highresolution ocean-atmosphere coupled circulation models. These simulations, carried out within the Process-Based Climate Simulation: Advances in High Resolution Modelling and European Climate Risk Assessment (PRIMAVERA-EU) project and designed with a coordinated experimental protocol (Haarsma et al. 2016), aimed to assess the impact of increased model horizontal resolution on a wide range of climate processes.

Importantly, this study does not attempt to minimize the documented major role of the WES feedback for explaining the evolution of the ENSO-related SST anomalies along the TNA during the spring season after the peak of the ENSO event. The main objective of this modeling study is to better understand the processes behind the initial SST gradient needed for triggering the WES feedback. We focus on understanding and quantifying the relative contributions of a thermodynamic (latent heat flux) and a dynamic (coastal upwelling) mechanism genesis to the appearance of the initial SST gradient in the case of the ENSO-TNA teleconnection. Please also note that although ENSO had been noted as driver of the AMM at interannual time scales (Taschetto et al. 2020), not all El Niño and La Niña episodes are followed by a positive and a negative AMM, respectively, due to internal variability of the Atlantic (Chang et al. 2006; Lee et al. 2008).
It is therefore necessary to clarify that we do not pretend to analyze here the full AMM variability at interannual time scales but the TNA SST response to ENSO.

According to the above, the present study addresses the following specific questions: 1) How El Niño/La Niña teleconnection with the TNA in spring is represented in oceanatmosphere coupled circulation models? 2) What are the large-scale and the regional-scale mechanisms involved? and 3) How is this teleconnection influenced by the nominal resolution of global circulation models?

The paper is organized as follows: Section 2 describes the data and methods used. In section 3, we describe and evaluate the representation of the ENSO teleconnection in oceanatmosphere coupled circulation models (hereinafter models for simplicity). Finally, section 4 gives a summary and a brief discussion to place our results in context with respect to the available literature.

\section{Data and methods}

In the present study we use six different models, each of which has a low-resolution and a high-resolution version. These models have been configured by six PRIMAVERA modeling groups and are part of the Tier 2 CMIP6HighResMIP coupled simulations (Haarsma et al. 2016). The models and resolutions used are detailed in Table 1. Please refer to the following references for further details regarding the model's characteristics: ECMWF-IFS (Roberts et al. 2018), CMCC-CM2 (Cherchi et al. 2019), CNRM-CM6 (Voldoire et al. 2019), MPI-ESM1.2 (Gutjahr et al. 2019), EC-Earth3P (Haarsma et al. 2020), and HadGEM3-GC3.1 (Roberts 2019).

Within the framework of these CMIP6-HighResMIP experiences, thirteen 100-yr-long control simulations (hereinafter 1950-piControl) and twenty-two 65-yr-long historical simulations from 1950 to 2014 (hereinafter 1950-hist), are used. These simulations have been selected among all available within PRIMAVERA according to the following constraints: 1) to analyze as many simulations as possible, and 2) to use a similar number of years among the models considered to create an unbiased multimodel ensemble mean. The resultant total amount of years analyzed is 2700 years. As will be shown in the next section, the approach is based on an empirical orthogonal function (EOF) analysis of El Niño/La Niña SST composites over the TNA from the aforementioned 1950-piControl and 1950-hist simulations. Considering the different time lengths of 1950-piControl (100 years) and 1950-hist (65 years) experiences, and with the intention of equitably weighting the years from these experiences, the 1950-piControl simulations are split in two parts (50 years long each). As a result, our EOF analyses are based on 48 SST composites obtained from simulated periods with similar time lengths: 26 composites based on 50-yr-long periods from the 1950-piControl simulations, and 22 composites based on 65-yr-long periods from the 1950hist simulations. The resultant principal components (PCs) have therefore 48 values, each associated with one of the aforementioned SST composites. These PCs are standardized, and the different variables of interest are regressed onto them. Prior to EOF analyses, all fields are linearly detrended. It is 


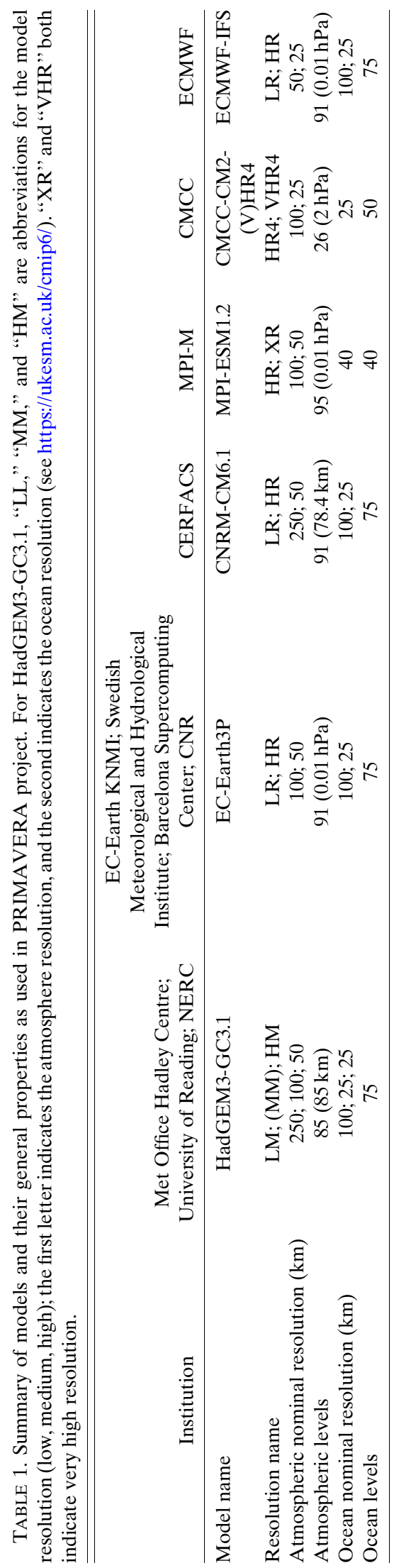

noteworthy that when atmospheric and oceanic variables are equivalent (e.g., ts and tos in the case of SST), the former is selected. Stream function and velocity potential have been obtained from the wind components via spherical harmonics. Unless otherwise indicated, the statistical significance is assessed by a bootstrap with replacement procedure (with 500 bootstrap replications).

To perform the EOF and subsequent analysis, all model variables are regridded to a common $1.5^{\circ} \times 1.5^{\circ}$ grid using bilinear interpolation. This will likely result in the loss of some small-scale differences among models. However, our primary objective in this study is analyzing the large-scale TNA SST response to ENSO rather than the smaller scale impacts.

Along the study, we repeatedly refer to the low-resolution (LR) and the high-resolution (HR) versions of models (or merely to the LR and the HR models for simplicity). The former groups those versions with lower resolution (including also the intermediate resolution in the case of HadGEM3GC3.1, see Tables 1 and 2). The rest of simulations groups therefore the HR versions of models.

\section{Results}

\section{a. Intermodel variability}

Both El Niño and La Niña signatures over the TNA SSTs in the February-April seasonal average after the peak of the ENSO episode present marked intermodel differences (see Fig. 1 and Fig. S1 in the online supplemental material, respectively). These signatures are based on El Niño/La Niña composites in January-March [Niño-3.4 index higher (lower) than $0.5(-0.5)$ standard deviations]. Most of the simulations reproduce the characteristic TNA warming but they also present significant differences in terms of amplitude and spatial pattern. In particular, the zonal SST gradient along the TNA and the meridional SST gradient between the TNA and the equatorial Atlantic, appear noticeably different in the set of simulations analyzed. This fact suggests different perturbations of the trade winds and/or distinct manifestations of the WES feedback. To make the interpretation of these intermodel differences easier, an EOF analysis of the residual TNA SST composites with respect to the observation, is obtained. These composites are performed by subtracting the observational TNA SST composite to that from each model $i$ (see Fig. 1 and Fig. S1). Please note that the aforementioned residuals can be interpreted as the systematic error or bias, for each model $i$, of the TNA SST response to ENSO. EOF analyses usually decompose an original field as $\sum \mathrm{EOF}$ (lat, lon $) \times \mathrm{PC}(t)$, where latitude (lat) and longitude (lon) are the space coordinates, and $t$ is the time. Here, however, the original field represents the aforementioned ENSO SST composites for different model simulations. Thus, our principal component is rather than a function of the time, a function of the simulation considered. It should be also noted that the resultant modes of variability obtained from the EOF are nondependent from the observational baseline used to compute the residuals.

The resultant leading modes are shown, for El Niño and La Niña episodes, in Fig. 2. Hereinafter all La Niña-related calculations are shown with reversed sign for a better comparison 
TABLE 2. Columns from left to right: 1) Simulation name (as in Fig. 1), 2) simulation order according to model nominal resolution (1-26 grouped here as LR models and 27-48 as HR models), and 3) classification of El Niño/La Niña TNA SST response according to the EOF analysis: PC values $>0.5 \mathrm{std} \operatorname{dev}$ (ON-TNA), PC values $<-0.5 \mathrm{std} \operatorname{dev}$ (OFF-TNA), and PC values $<0.5$ std dev and $>-0.5$ std dev (realistic).

\begin{tabular}{|c|c|c|c|}
\hline Simulation order & Simulation No. & Classification Niño response & Classification Niña response \\
\hline HadGEM3-GC3.1 (LM) 1950-99 & 1 & Realistic & OFF-TNA \\
\hline HadGEM3-GC3.1 (LM) 2000-50 & 2 & OFF-TNA & Realistic \\
\hline HadGEM3-GC3.1 (LM) r1 & 3 & Realistic & OFF-TNA \\
\hline HadGEM3-GC3.1 (LM) r2 & 4 & ON-TNA & Realistic \\
\hline CNRM-CM6.1 (LR) 1950-99 & 5 & Realistic & OFF-TNA \\
\hline CNRM-CM6.1 (LR) 2000-49 & 6 & OFF-TNA & OFF-TNA \\
\hline CNRM-CM6.1 (LR) r1 & 7 & OFF-TNA & OFF-TNA \\
\hline CNRM-CM6.1 (LR) r2 & 8 & Realistic & OFF-TNA \\
\hline CMCC-CM2 (HR4) 1950-99 & 9 & Realistic & ON-TNA \\
\hline CMCC-CM2 (HR4) 2000-50 & 10 & ON-TNA & Realistic \\
\hline CMCC-CM2 (HR4) r1 & 11 & ON-TNA & ON-TNA \\
\hline ECMWF-IFS (LR) 1950-99 & 12 & ON-TNA & Realistic \\
\hline ECMWF-IFS (LR) 2000-49 & 13 & Realistic & Realistic \\
\hline ECMWF-IFS (LR) r1 & 14 & Realistic & Realistic \\
\hline ECMWF-IFS (LR) r2 & 15 & Realistic & Realistic \\
\hline MPI-ESM1.2 (HR) 1950-99 & 16 & ON-TNA & Realistic \\
\hline MPI-ESM1.2 (HR) 2000-50 & 17 & ON-TNA & Realistic \\
\hline MPI-ESM1.2 (HR) r1 & 18 & Realistic & ON-TNA \\
\hline EC-Earth3P (LR) 1950-99 & 19 & Realistic & OFF-TNA \\
\hline EC-Earth3P (LR) 2000-49 & 20 & OFF-TNA & OFF-TNA \\
\hline EC-Earth3P (LR) r1 & 21 & Realistic & OFF-TNA \\
\hline EC-Earth3P (LR) r2 & 22 & Realistic & OFF-TNA \\
\hline HadGEM3-GC3.1 (MM) 1950-99 & 23 & ON-TNA & ON-TNA \\
\hline HadGEM3-GC3.1 (MM) 2000-50 & 24 & OFF-TNA & Realistic \\
\hline HadGEM3-GC3.1 (MM) r1 & 25 & Realistic & ON-TNA \\
\hline HadGEM3-GC3.1 (MM) r2 & 26 & Realistic & Realistic \\
\hline CNRM-CM6.1 (HR) 1950-99 & 27 & Realistic & ON-TNA \\
\hline CNRM-CM6.1 (HR) 2000-49 & 28 & OFF-TNA & OFF-TNA \\
\hline CNRM-CM6.1 (HR) r1 & 29 & Realistic & Realistic \\
\hline CNRM-CM6.1 (HR) r2 & 30 & OFF-TNA & Realistic \\
\hline ECMWF-IFS (HR) 1950-99 & 31 & ON-TNA & Realistic \\
\hline ECMWF-IFS (HR) 2000-49 & 32 & ON-TNA & Realistic \\
\hline ECMWF-IFS (HR) r1 & 33 & ON-TNA & ON-TNA \\
\hline ECMWF-IFS (HR) r2 & 34 & ON-TNA & Realistic \\
\hline MPI-ESM1.2 (XR) 1950-99 & 35 & OFF-TNA & OFF-TNA \\
\hline MPI-ESM1.2 (XR) 2000-50 & 36 & OFF-TNA & OFF-TNA \\
\hline MPI-ESM1.2 (XR) r1 & 37 & Realistic & Realistic \\
\hline EC-Earth3P (HR) 1950-99 & 38 & Realistic & Realistic \\
\hline EC-Earth3P (HR) 2000-49 & 39 & OFF-TNA & OFF-TNA \\
\hline EC-Earth3P (HR) r1 & 40 & Realistic & OFF-TNA \\
\hline EC-Earth3P (HR) r2 & 41 & OFF-TNA & Realistic \\
\hline HadGEM3-GC3.1 (HM) 1950-99 & 42 & OFF-TNA & ON-TNA \\
\hline HadGEM3-GC3.1 (HM) 2000-50 & 43 & Realistic & OFF-TNA \\
\hline HadGEM3-GC3.1 (HM) r1 & 44 & OFF-TNA & Realistic \\
\hline HadGEM3-GC3.1 (HM) r2 & 45 & ON-TNA & Realistic \\
\hline CMCC-CM2 (VHR4) 1950-99 & 46 & ON-TNA & ON-TNA \\
\hline CMCC-CM2 (VHR4) 2000-50 & 47 & ON-TNA & ON-TNA \\
\hline CMCC-CM2 (VHR4) r1 & 48 & ON-TNA & ON-TNA \\
\hline
\end{tabular}

with El Niño patterns. Leading modes capture, approximately, half of the total variance $(52 \%$ for El Niño and $47 \%$ for $\mathrm{La}$ Niña) of the intermodel spread in the TNA response to ENSO. The Atlantic SSTs associated with the leading modes highlight the AMM-like spatial structure of the ENSO signature (Fig. 2; upper panels). Apart from the Atlantic SST anomalies, the main anomalies in Fig. 2 appear over the tropical Pacific. As we will discuss below this fact points to El Niño/La Niña amplitude as an important factor behind the diversity of TNA responses among the models analyzed. The associated PCs are also shown and ordered by the corresponding nominal resolution of the models (Fig. 2; bottom panels). As mentioned above, each 


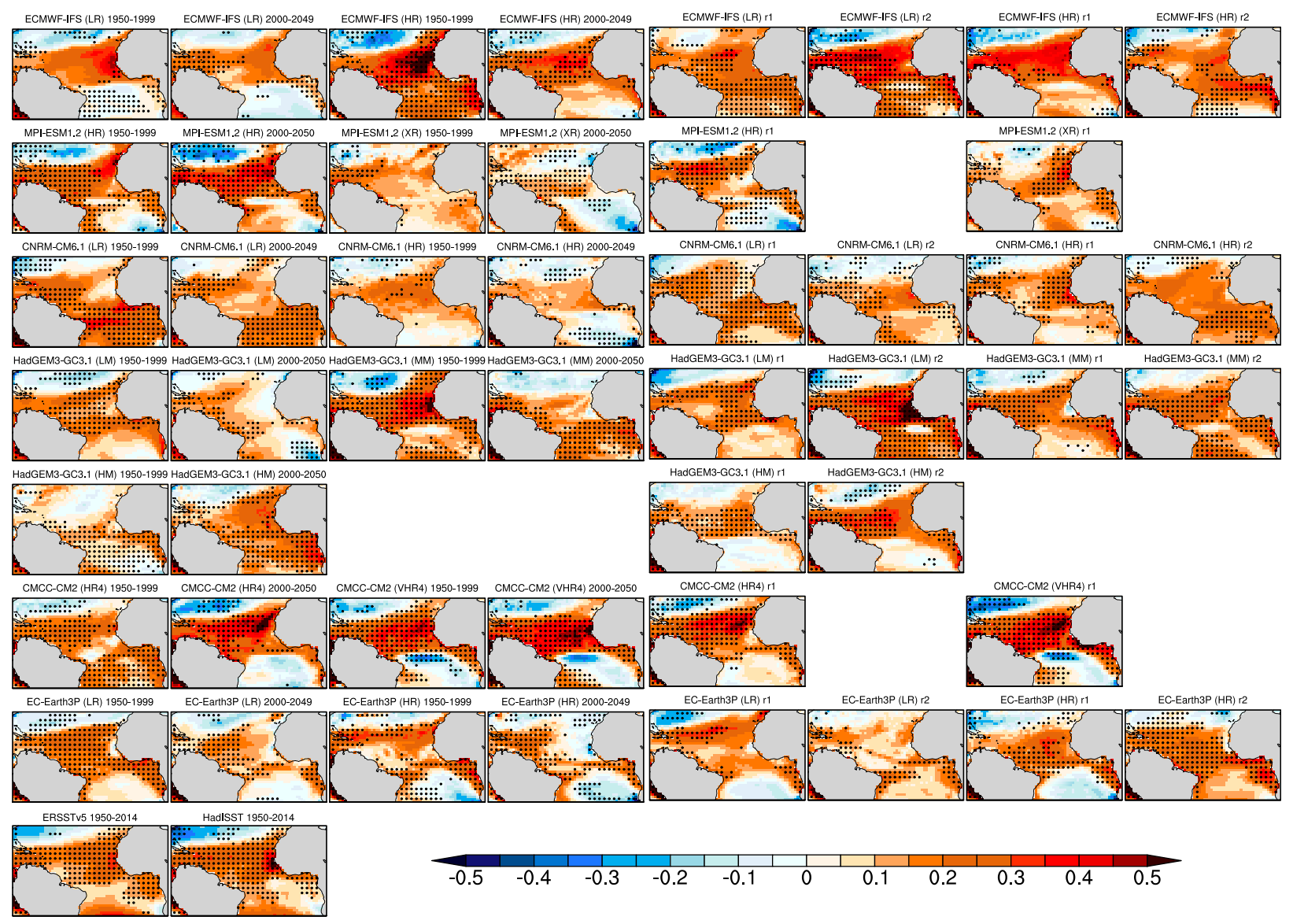

FIG. 1. For each PRIMAVERA simulation analyzed in the present study, tropical North Atlantic February-April SST composite (shaded; K) based on El Niño years (Niño-3.4 index in January-March higher than 0.5 standard deviations). To facilitate understanding, panels have been ordered by model. The bottom-left panels correspond to the same composite in ERSSTv5 and HadISST databases. Black marks indicate SST significant anomalies at a 95\% significance level.

value of these PCs represents, by construction, a particular El Niño/La Niña SST composite obtained from an individual simulation. In particular, positive PC values represent simulations that overestimate the TNA SST response to ENSO while negative $\mathrm{PC}$ values represent simulations that underestimate this response. We will refer these features as "ONTNA" and "OFF-TNA," respectively (see Table 2). At first glance, there does not seem to be a direct relationship between the horizontal resolution of the models and the ENSO impact over the TNA: ON-TNA and OFF-TNA responses are broadly in balance in LR and HR models.

\section{b. The role of El Niño/La Niña amplitude and persistence}

Figure 3 shows, for each case (El Niño/La Niña vs ONTNA/OFF-TNA), the winter response of SST, surface wind, and 300-hPa streamfunction. Over the tropical Pacific, two twin upperlevel anomalous anticyclones straddling the equator appear. This structure is consistent with the well documented tropical GillMatsuno response to ENSO, with the upper-level Rossby gyres located slightly to the west of the maximum divergence (Fig. S2). Over the tropical Atlantic, a secondary Gill-type response is identified (Fig. 3). This pattern, opposite in sign to that in the central Pacific, is associated with the zonal compensation of the anomalous Walker cell generated by El Niño/La Niña SST anomalies (Fig. S2). The wavy activity at midlatitudes reflects the PNA pattern also consistent with the Rossby wave train's propagation associated with the ENSO-TNA teleconnection (Enfield and Mayer 1997). The upper-tropospheric response to both $\mathrm{El}$ Niño and La Niña events is noticeably stronger in ON-TNA models than in OFFTNA models. As a result, only in the former case the TNA trade winds are perturbed and an anomalous SST warming emerges close to the African coast. These differences over the TNA among models with ON-TNA and OFF-TNA responses, already visible in winter, point to the amplitude of El Niño/La Niña episodes in each model as a major driver of these differences.

The role played by the amplitude of El Niño/La Niña events is further assessed by calculating the monthly evolution of the Niño-3.4 index in models with distinct responses (ON-TNA vs OFF-TNA) and spatial resolutions (LR vs HR). Regarding El Niño (Fig. 4; right panel) both LR and HR models, present an ON-TNA response in combination with high SST anomalies over the tropical Pacific. On the contrary, the Niño-3.4 index 

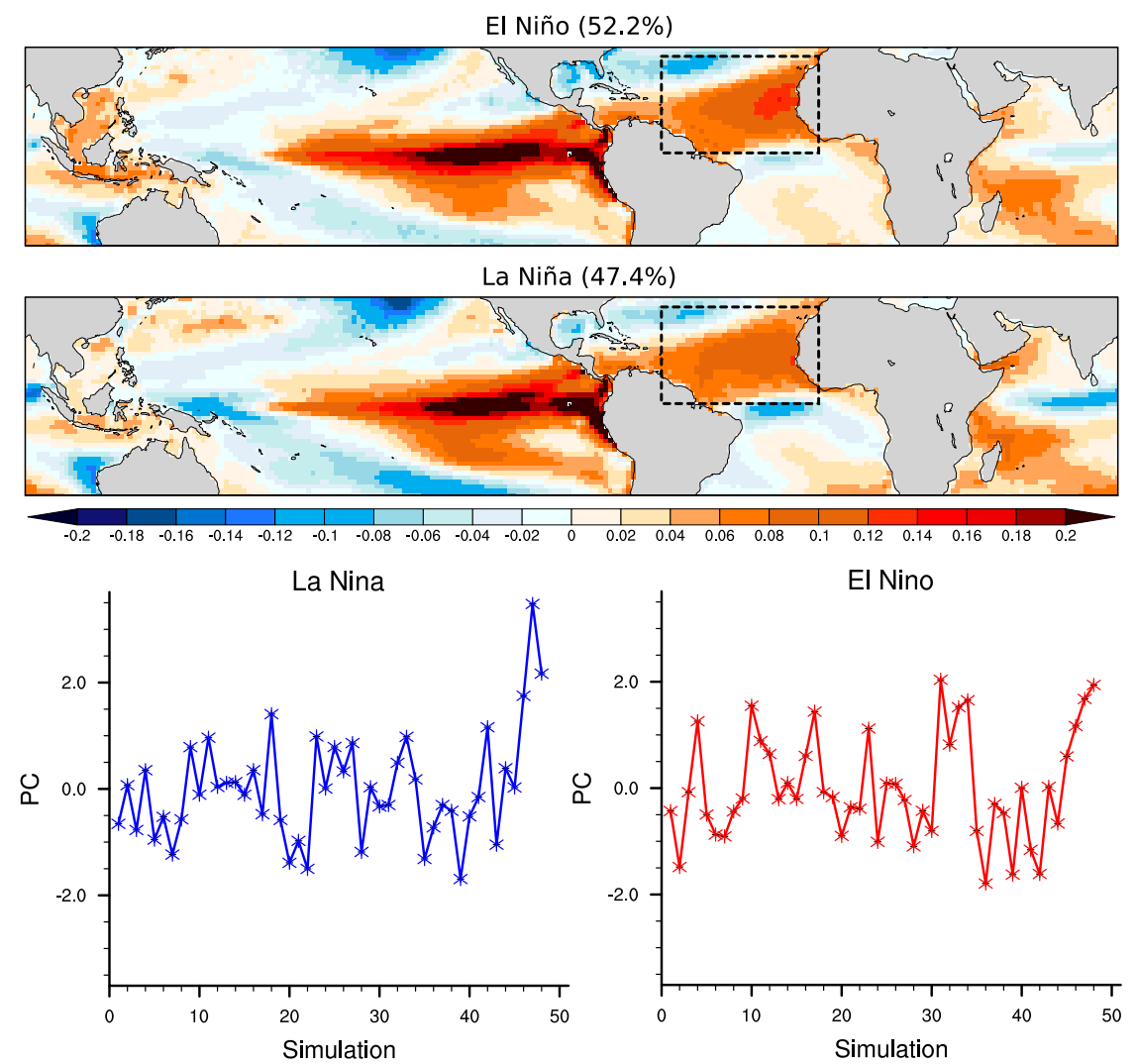

FIG. 2. The leading modes of variability obtained from the EOF analysis of El Niño and La Niña February-April SST composites over the TNA region and for PRIMAVERA simulations (see Fig. 1). These composites are in turn based on the standardized Niño-3.4 index in January-March higher than 0.5 standard deviations (std dev) or weaker than $-0.5 \mathrm{std} \mathrm{dev}$, respectively. (top),(middle) Regression onto the global SSTs of the corresponding leading mode. The percentage of variance explained is shown in the title. The dashed box indicates the TNA region considered for computing the EOF. Units are K per standard deviation of the PC. (bottom) The corresponding standardized PC ordered from coarser to finer model nominal resolution (see simulation numbering in Table 2).

for those models with an OFF-TNA response is significantly lower. This difference in the Niño-3.4 index among ON-TNA and OFF-TNA responses appears in winter and spring season, suggesting that not only the amplitude but also the persistence of the tropical Pacific SSTs are important. The same feature is identified for La Niña episodes in HR models (Fig. 4; left panel), but in the case of LR models similar amplitudes of the Niño-3.4 index are shown for both ON-TNA and OFF-TNA cases. This suggests that, at least in the latter case, the SST anomalies in the tropical Pacific should not be the only factor explaining the intermodel spread in the TNA response.

\section{c. The processes involved in the TNA}

In the previous section we analyzed the role of El Niño/La Niña amplitude (and related teleconnection) for triggering a response over the TNA. Nevertheless, the way by which the anomalous ENSO-related winds alter the SST over the TNA has not been addressed. As noted in the introduction section, this has been usually explained by the WES feedback. However, the mechanism behind the initial SST anomalies, those that are necessary for triggering the WES feedback, remains unclear. As shown in Fig. 5 for ON-TNA models (see OFF-TNA models in Fig. S3), these SST anomalies emerge in winter in the eastern part of the TNA off the African coast. These anomalies increase and propagate to the west, together with the interhemispheric SST gradient, as the spring season progresses. A similar movement from east to west is obtained for the cross-equatorial surface wind anomalies. This response in both SST and surface winds highlights the role played by the WES feedback in amplifying and sustaining the AMM along the spring season. However, the mechanism behind the initial SST anomalies in January-February off the African coast is subject to considerable uncertainties.

Two hypotheses are now considered to better understand the relative influence of the dynamic and the thermodynamic processes in triggering theses SST anomalies. To this aim, the meridional wind stress $\left(\tau_{y}\right)$ and the latent heat flux $\left(Q_{\text {lat }}\right)$ at surface levels are averaged, for each month, over the aforementioned region off the African continent (see the magenta box in the topleft panel of Fig. 5). In particular we select the latitude lat $t_{\max }$, where the coastal SST anomaly in January-February within the region $\left(15^{\circ}-21^{\circ} \mathrm{N}, 18^{\circ}-16.5^{\circ} \mathrm{W}\right)$ is maximum, and we average $\tau_{y}$ 


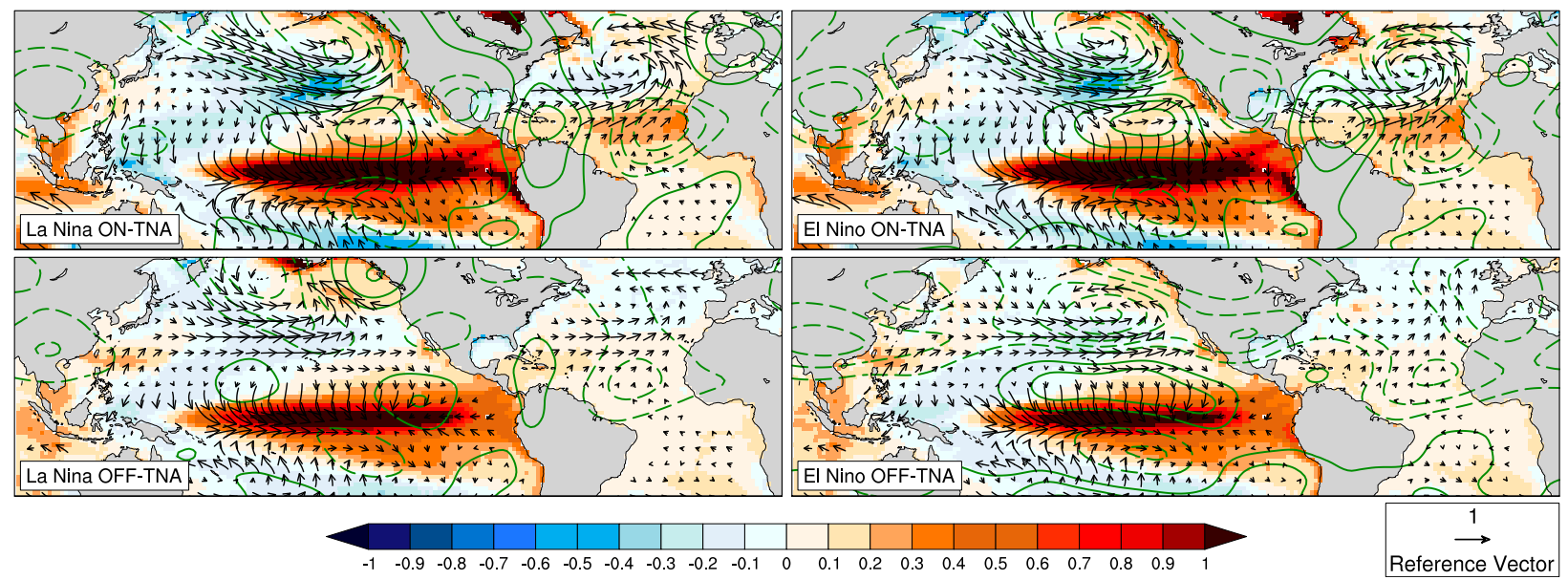

FIG. 3. SST (shaded; K), surface wind (vectors; $\mathrm{m} \mathrm{s}^{-1}$ ), and streamfunction at $300 \mathrm{hPa}$ (contoured; contour interval $=5 \times 10^{5} \mathrm{~m} \mathrm{~s}^{-2}$ ) anomalous composites averaged in January-February. They are based on both the standardized Niño-3.4 index and the PC obtained from the EOF analysis (Fig. 2), as follows: El Niño ON-TNA (Niño-3.4 index $>0.5$ std dev and PC $>0.5$ std dev), El Niño OFF-TNA (Niño-3.4 index $>0.5$ std dev and PC $<-0.5$ std dev), La Niña ON-TNA (Niño-3.4 index $<-0.5$ std dev and PC $>0.5$ std dev), and La Niña OFFTNA (Niño-3.4 index $<-0.5$ std dev and $\mathrm{PC}<-0.5$ std dev).

and $Q_{\text {lat }}$ as follows: $x_{\text {index }}=\bar{X}_{\left[\left(24^{\circ} \mathrm{W}\right)-\left(16.5^{\circ} \mathrm{W}\right),\left(\operatorname{lat}_{\max }-1.5\right)-\left(\mathrm{lat}_{\max }+3\right)\right]}$. We use these indices to characterize two different contributions (both forced by the anomalous winds) to the heat budget of the ocean mixed layer: the dynamic (coastal upwelling) and the thermodynamic (evaporation). Please note that according to the northsouth configuration of the northwest African region where the initial SST anomalies appear in Fig. 5, the ocean Ekman transport (coastal upwelling) is proportional to the meridional component of the wind stress $\tau_{y}$. Hence, we used the variability of the meridional wind stress to characterize, as a first-order approximation, the variability of the coastal upwelling in our region of interest.

Figure 6 shows for both El Niño and La Niña events the PC of the variability mode in February-April (see Fig. 2) against the above mentioned dynamic (coastal upwelling) and thermodynamic (evaporation) indices calculated from January to
April. Please note how each point in Fig. 6 refers to a unique El Niño/La Niña TNA SST composite from a particular model (see Fig. 1 and Fig. S1), all of them being used here to carry on our EOF analysis (Fig. 2). Regarding the latent heat flux, no link is found for La Niña events and a weak link is suggested in February for El Niño events (Fig. 6; upper panels). The latter is also reproduced when the net heat fluxes at surface (instead of $Q_{\text {lat }}$ ) is used for computing the horizontal axis (not shown). However, if $Q_{\text {lat }}$ is subtracted from the net heat fluxes the aforementioned link with PC disappears (not shown). This suggests a weak but significant role of the surface latent heat flux anomalies in February in modulating the subsequent TNA SST response to ENSO in spring.

In contrast, a robust linear relationship emerges with the Ekman transport (Fig. 6; bottom panels). Although the latter presents substantial dispersion, which indicates a large
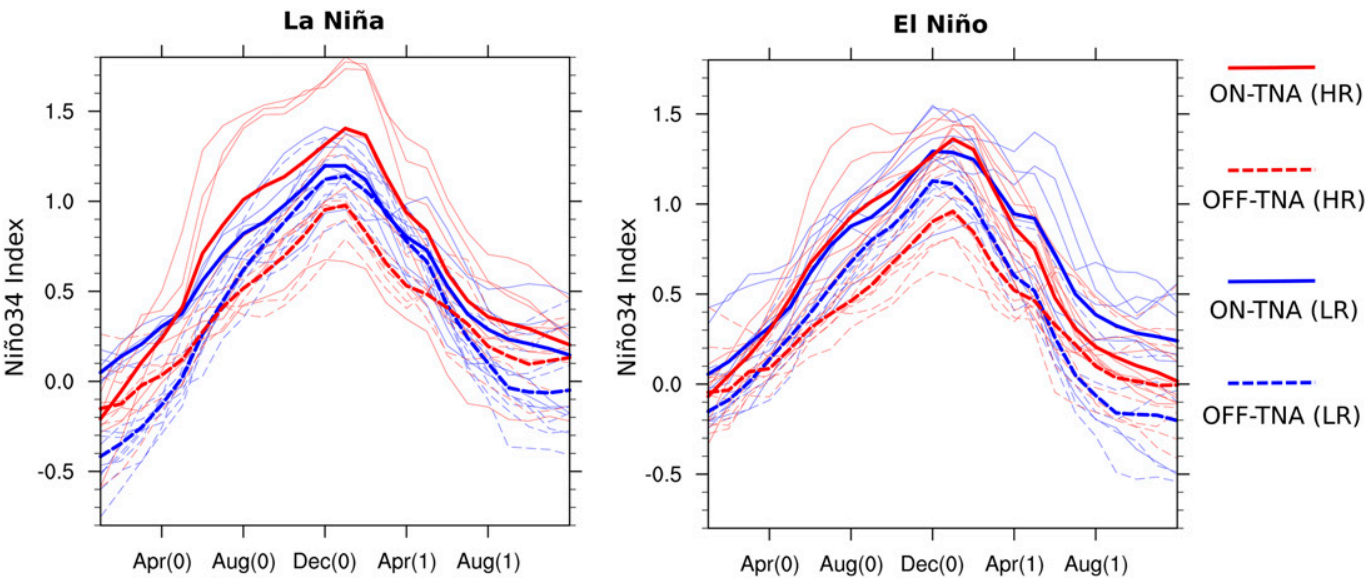

FIG. 4. Monthly evolution of the standardized Niño-3.4 index (K) for each model (thin lines) and sample of models (solid lines) analyzed. Please note that the TNA SST response analyzed here occurs during the spring season of year 1 (after the peak of El Niño/La Niña episode in the tropical Pacific). 

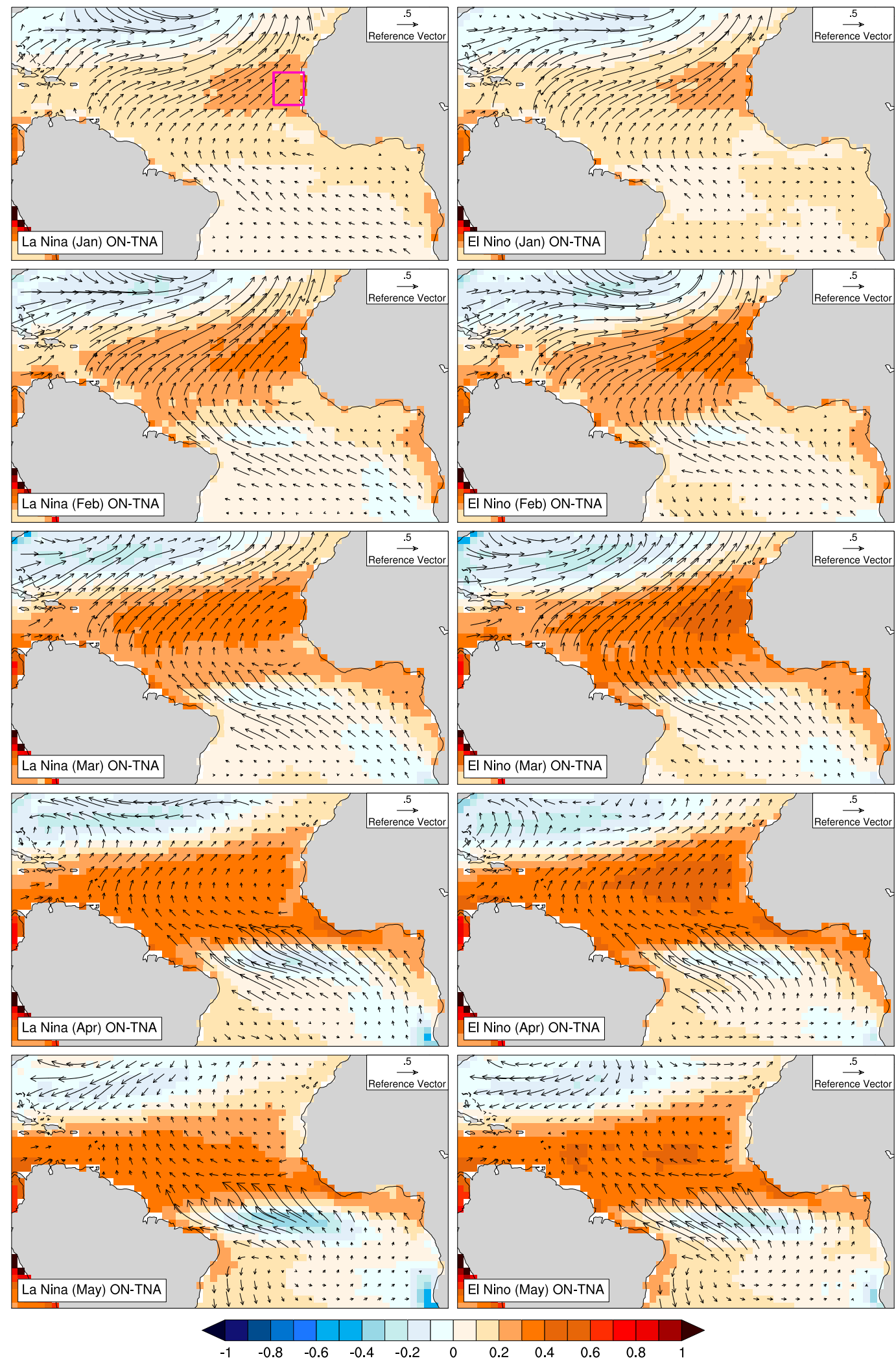

FIG. 5. Monthly SST (shaded; K) and surface wind (vectors; $\mathrm{m} \mathrm{s}^{-1}$ ) anomalous composites associated with ON-TNA responses. (left) La Niña episodes (Niño-3.4 index $<-0.5 \mathrm{std}$ dev and PC $>0.5 \mathrm{std}$ dev) and (right) El Niño episodes (Niño-3.4 index $>0.5 \mathrm{std} \mathrm{dev}$ and PC $>0.5 \mathrm{std} \mathrm{dev}$ ). The evolution from January to April is shown from top to bottom. 

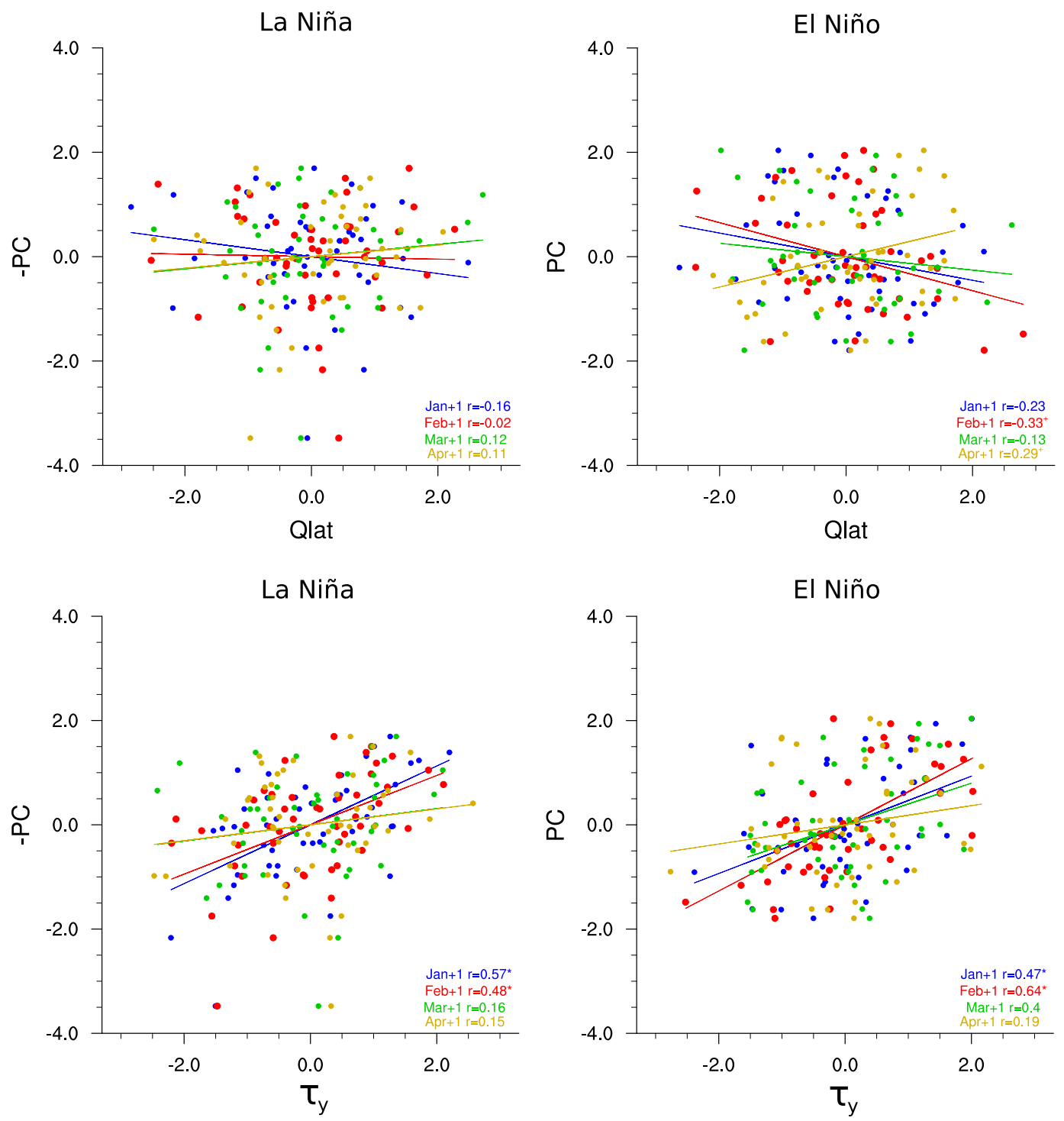

FIG. 6. Scatterplot between the PC of the TNA variability mode in February-April (see Fig. 2) against the monthly $Q_{\text {lat }}$ and $\tau_{y}$ indices off the African coast. Both the PC and the spatial indices $\left(Q_{\text {lat }}\right.$ and $\left.\tau_{y}\right)$ are standardized. These indices are computed within a region off the northwest African coast (broadly illustrated with a magenta box in the top-left panel of Fig. 5). In particular, $\tau_{y}$ and $Q_{\text {lat }}$ indices are averaged as follows: $x_{\text {index }}=\bar{X}_{\left[\left(24^{\circ} \mathrm{W}\right)-\left(16.5^{\circ} \mathrm{W}\right),\left(\mathrm{lat}_{\max }-1.5\right)-\left(\mathrm{lat}_{\max }+3\right)\right]}$, lat ${ }_{\max }$ being the latitude where coastal SST anomaly in January-February is maximum within the region $\left(18^{\circ}-16.5^{\circ} \mathrm{W}, 15^{\circ}-21^{\circ} \mathrm{N}\right)$. The linear correlation coefficients are shown in the bottom-right side ( + and $*$ indicate $95 \%$ and $99 \%$ confidence levels assessed with a two-tailed $t$ test).

intermodel spread in the TNA SST response to ENSO not directly related to the coastal upwelling, it has statistically significant correlation coefficients (above 99\% significance) in January and February for both, El Niño and La Niña. These correlations indicate an anomalous warming (cooling) of the TNA in February-April associated with a weakening (strengthening) of the ocean Ekman transport in winter (JanuaryFebruary) off the northwest African coast. This suggests a modest but robust and consistent role of the Canary Upwelling System in winter in the development of the ENSO teleconnection with the TNA SSTs in spring.
To assess the influence of horizontal resolution of models for representing this link between the coastal upwelling off the African coast and the TNA SSTs, the previous correlation analysis with the Ekman transport has been repeated for LR and HR models independently. We focus on the Ekman transport in the January-February seasonal average, selecting the months for which the correlation in Fig. 6 is maximum and significant at a $99 \%$ significance level. The resultant scatterplots are shown for El Niño and La Niña events in Fig. 7 (upper panels). The link, although significant in all cases, appears weakened in LR models and reinforced in HR 
La Niña (LR vs HR)

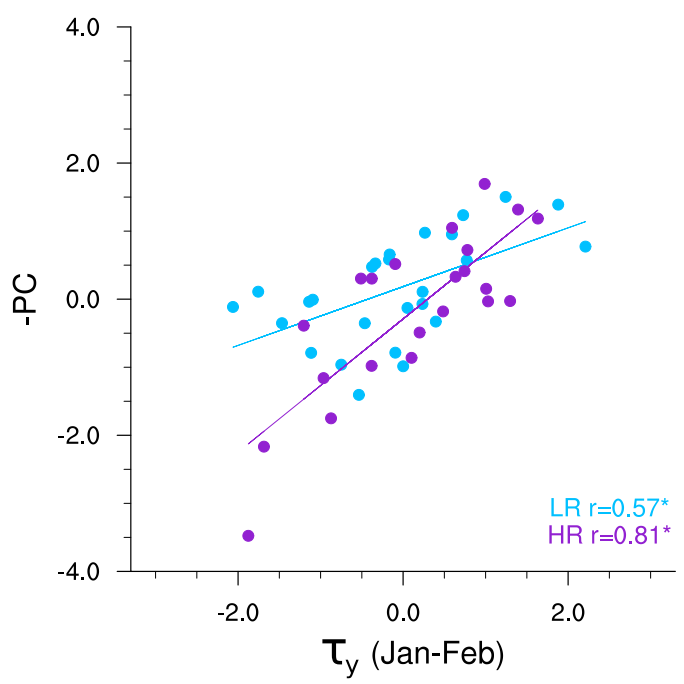

La Niña (LR vs HR)

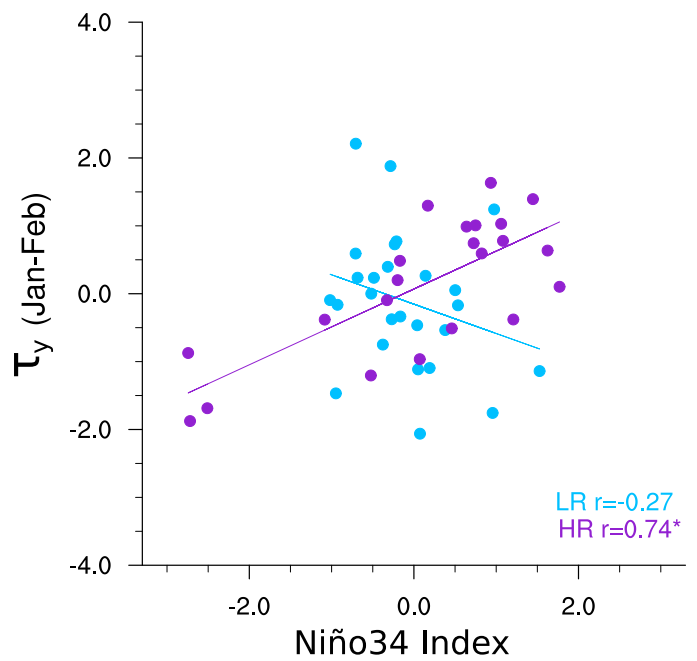

El Niño (LR vs HR)

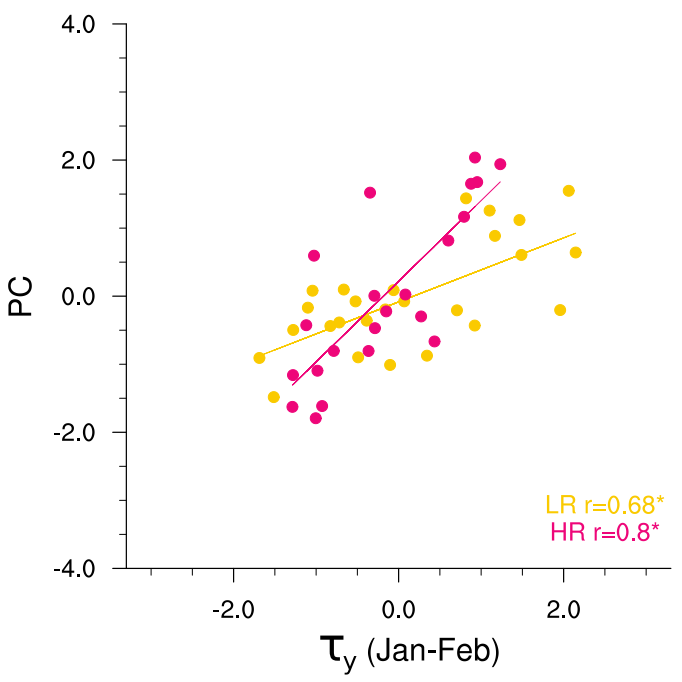

El Niño (LR vs HR)

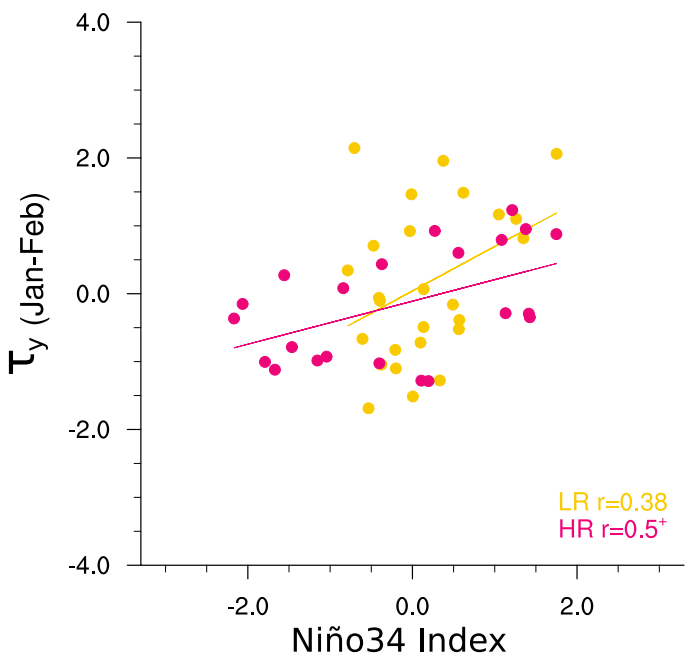

FIG. 7. (top) As in bottom panels in Fig. 6, but separating LR and HR models. (bottom) Scatterplots between the Ekman transport averaged off the African coast and the January-March Niño-3.4 index. The upwelling index $\left(\tau_{y}\right)$ is averaged in January-February in accordance with those months for which the correlation in Fig. 6 is maximum and significant at a 99\% significance level. As in Fig. 6, the linear correlation coefficients are shown in the bottom-right side ( + and $*$ indicate $95 \%$ and $99 \%$ confidence levels assessed with a two-tailed $t$ test).

models, obtaining in the latter case a $99 \%$ significant correlation coefficient of 0.8 for both El Niño and La Niña episodes. As shown, not only the correlation is higher in HR models than in LR models, but also the slope of the resultant linear trends. These parameters offer distinct and complementary information: 1 ) a better fit between coastal upwelling and the AMM-like response in HR models (correlation coefficient) and 2) a stronger susceptibility of the AMM-like response to perturbations in the coastal upwelling in HR models (slope). This result highlights the close link (reinforced in HR models) between the coastal upwelling intensity in January-February off the African coast and the subsequent development of the AMM in spring. However, only the coastal upwelling in HR models seems to be affected by the amplitude of El Niño/La Niña forcing (Fig. 7; bottom panels). Why the coastal upwelling in HR models is sensitive to the amplitude of the ENSO-related anomalies and the coastal upwelling in LR models is not? This suggests the existence of a differential factor related to model horizontal resolution. This question is the subject of the following section.

\section{d. The role of the background conditions in the Atlantic}

The depth of the ocean mixed layer (i.e., the position of the thermocline) is an active part of the marine environment that strongly influences the ocean-atmosphere coupling. It is then interesting to compare the mean state conditions of the mixed 


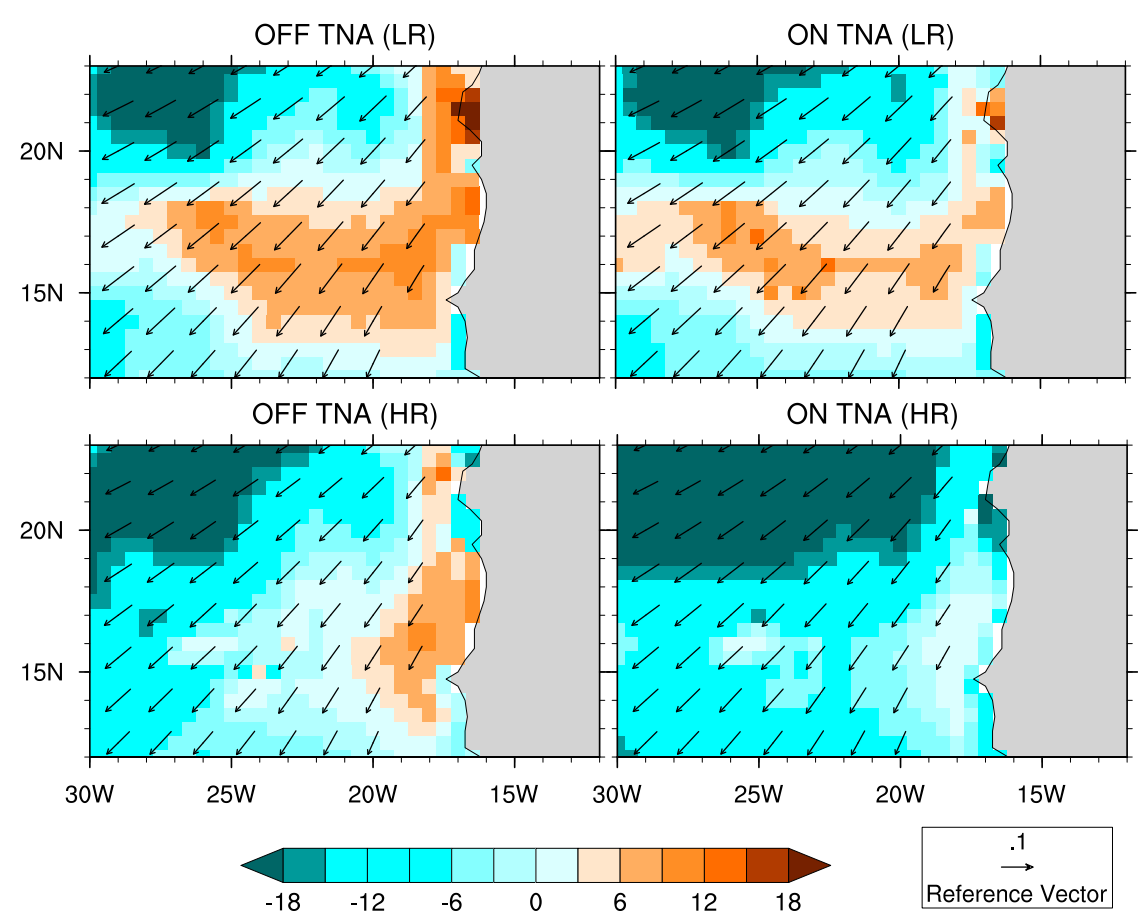

FIG. 8. Climatological mixed layer depth bias (shaded; $m$ ) and climatological surface winds (vectors; $\mathrm{m} \mathrm{s}^{-1}$ ) in January-February in models with distinct El Niño impacts (ON-TNA vs OFF-TNA) and spatial resolutions (LR vs HR).

layer depth in those models whose El Niño/La Niña teleconnection with the TNA is ON-TNA-like or OFF-TNA-like. The corresponding bias of the mixed layer depth is shown for El Niño and both LR and HR models in Fig. 8. The same figure for La Niña is included in the supplemental material (Fig. S4). In particular, we focus on the ocean region off the African coast (to the east of $24^{\circ} \mathrm{W}$ ) where the initial SST anomalies associated with ENSO emerge in winter (i.e., the region within the magenta box in Fig. 5).

As shown in Fig. 8, models tend to overestimate the mixed layer depth along the northwest African coast. Although both LR and HR models present a thinner mixed layer depth for ON-TNA responses than for OFF-TNA responses, HR models reduce the mixed layer depth bias regardless the impact of the ENSO-related anomalous winds (i.e., ON-TNA) or not (i.e., OFF-TNA). The same conclusion can be derived from La Niña episodes (Fig. S4). This thinner and more realistic representation of the mixed layer depth in HR models is consistent with the conclusion derived in the previous subsection: a stronger effect of the ENSO-related winds on the Canary Upwelling System in HR models than in LR models. The sketch in Fig. 9 visually summarizes this reasoning whereby the ocean mean state modulates the impact of the anomalous wind on the anomalous coastal upwelling.

It is noteworthy that other factors than the mixed layer depth mean state might be influencing the coupling between the ENSO-related winds and coastal upwelling. For instance, the mean state of the local wind stress could alter the effectiveness of the anomalous ENSO-related winds to perturb the subsurface ocean. However, the differences among LR and
HR models in the mean state of the wind stress (see vectors in Fig. 8) are negligible with respect to the differences identified in the ocean mean state (shaded in Fig. 8).

\section{e. Implications for predictability}

According to what has been mentioned above, an ensemble mean obtained from models with different horizontal resolutions (LR vs HR) may lead to underestimate (OFF-TNA) or overestimate (ON-TNA) the ENSO-TNA teleconnection. A remaining question is how this issue will affect the SST signal-

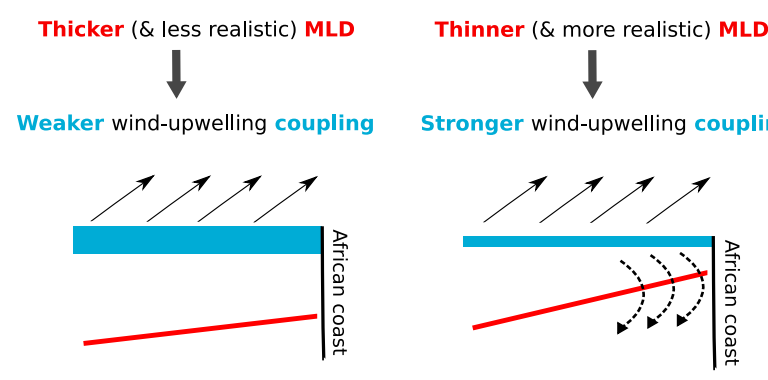

FIG. 9. Schematic of the two distinct responses that the same ENSO-related winds can produce on the Canary Upwelling System depending on the mixed layer depth (MLD) mean state conditions. Solid arrows represent the anomalous El Niño winds off the African coast in January-February (see top panels in Fig. 5) and dashed arrows represent the related anomalous impact on the upwelling (downwelling in this case). Red lines broadly symbolize the mean state of the mixed layer depth in (left) LR and (right) HR models. 

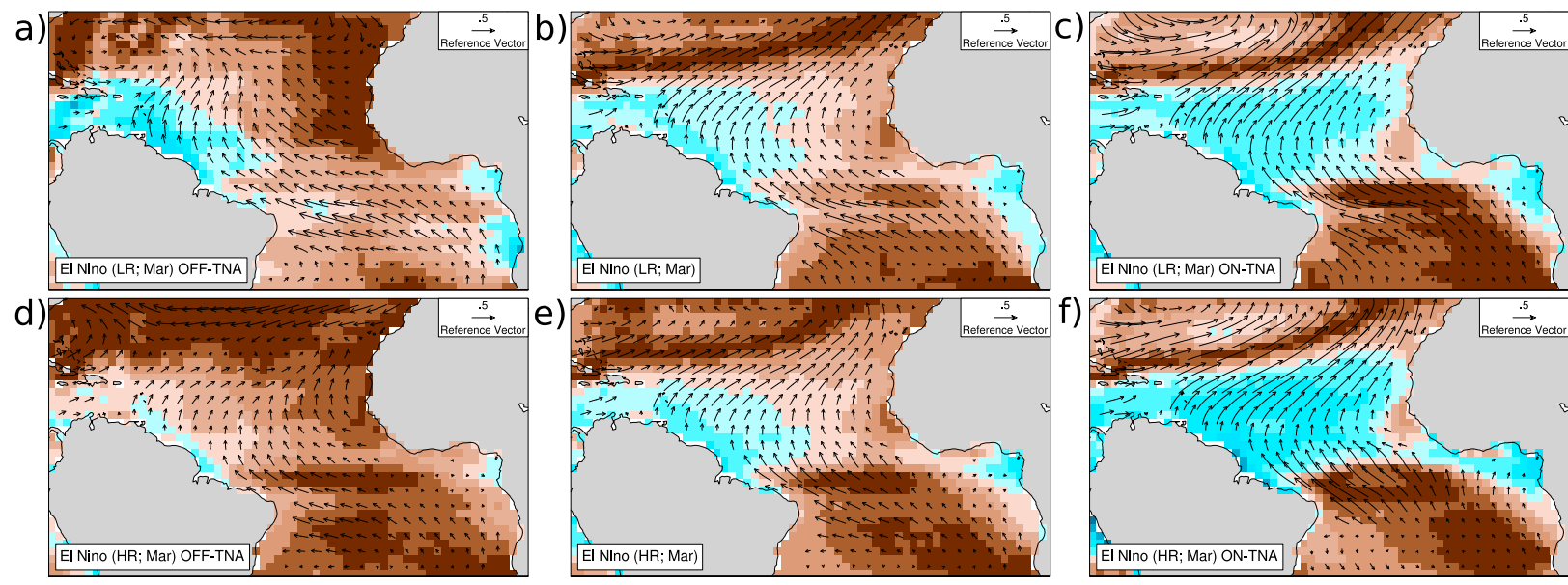

e)

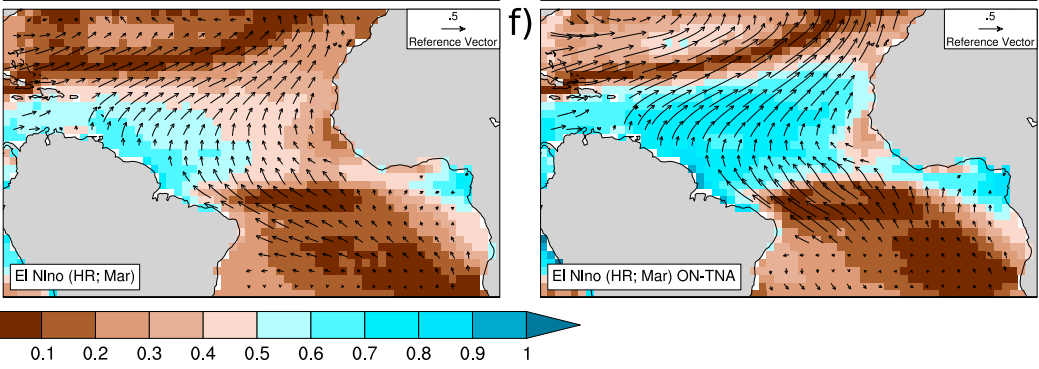

FIG. 10. For El Niño episodes the SST signal-to-noise ratio (shaded) and the anomalous surface wind (vectors $\mathrm{m} \mathrm{s}^{-1}$ ) in March over the Atlantic basin. The ratio is computed as the magnitude of the ensemble mean response divided by the intraensemble standard deviation. The calculation considering (left) OFF-TNA models, (center) all models, and (right) ON-TNA models. (a)-(c) LR models; (d)-(f) HR models.

to-noise ratio related to this teleconnection (i.e., the ratio between the predictable and unpredictable components) and, hence, its potential predictability. To this aim the simplest SST signal-to-noise ratio computed with all the models available has been compared to those ratios obtained from the OFFTNA and the ON-TNA subsamples of models. They are shown, respectively, in the central, left, and right panels of Fig. 10 (El Niño) and Fig. 11 (La Niña). Furthermore, LR (upper panels) and HR (bottom panels) models have been analyzed separately in order to infer the role played by horizontal resolution.

A common feature among the aforementioned SST signalto-noise ratios is that higher values emerge in the western TNA while lower values appear in the eastern TNA. This is not surprising since the interannual SST variance in the eastern TNA is higher than in the western TNA, which leads to a weak predictability in the former case (García-Serrano et al. 2017). However, there are some interesting differences among the signal-to-noise ratios shown in Figs. 10 and 11. As expected, predictability increases in ON-TNA models (right panels) and decreases in OFF-TNA models (left panels), since the signal (i.e., the magnitude of the ensemble mean response) is overestimated in the former case and underestimated in the latter case. Interestingly, this contrast among ON-TNA and OFF-TNA models is intensified in HR models (Figs. 10d-f and 11d-f). Thus, HR models do not always lead to improved predictability and more realistic results compared to LR models. This is coherent with the stronger ocean-atmospheric
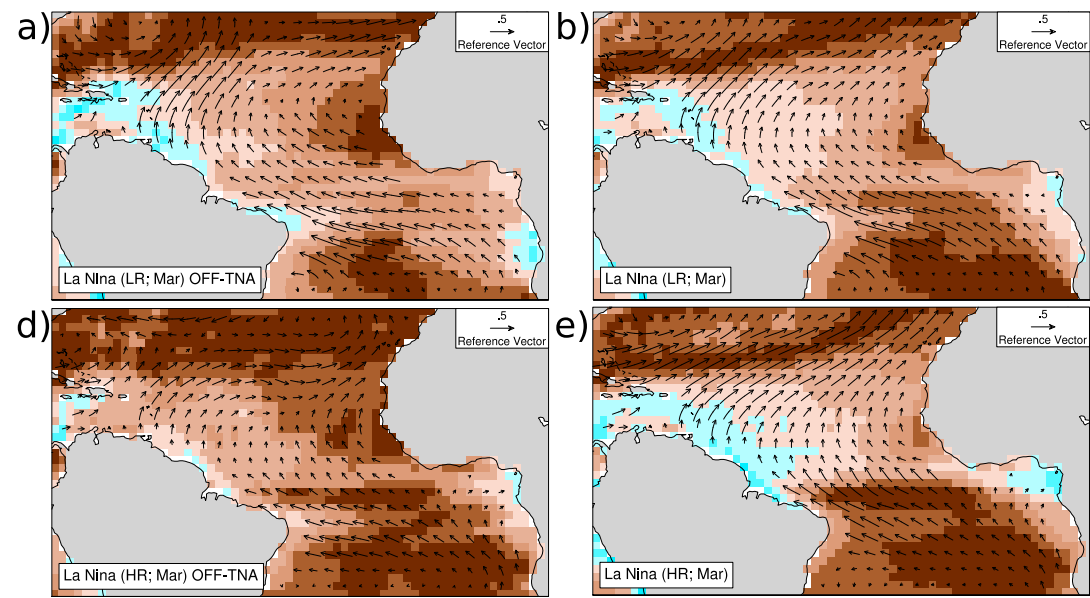

e)

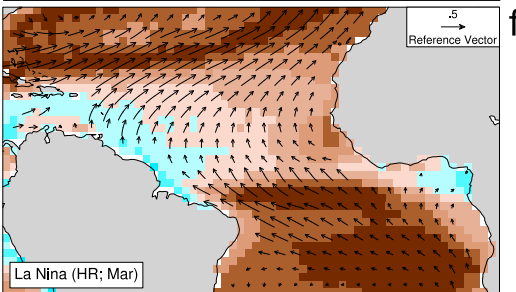

La Nina (HR; Mar)
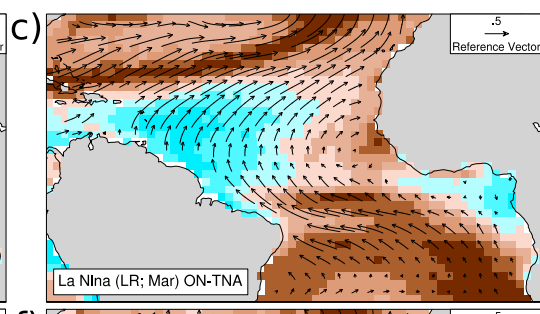

f)

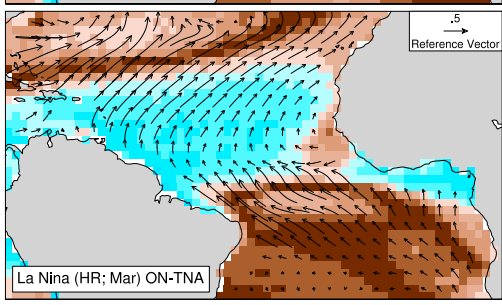

FIG. 11. As in Fig. 10, but for La Niña episodes. 
coupling identified off the African coast, and the related impact on the AMM, in HR models (Fig. 7). Thus, under similar errors in the anomalous winds (ON-TNA like or OFF-TNA like), HR models can produce even less realistic TNA SST responses than LR models.

\section{Summary and brief discussion}

This modeling study characterizes the ENSO-TNA teleconnection in models with different horizontal resolutions. To this aim, we use a modern set of simulations made within the PRIMAVERA-EU project and designed with a coordinated experimental protocol. This set has allowed us to analyze the role played by horizontal resolution of models to reproduce the observed impact of ENSO on the TNA SSTs in boreal spring. This ENSO signature projects onto the AMM, one of the most significant SST modes of the tropical Atlantic. The AMM is explained by the WES feedback, which requires the existence of an initial SST gradient. To better understand the processes behind this initial SST gradient in the case of the ENSO-TNA teleconnection is the main objective of the present study.

The presented results indicate that the ENSO-related winds over the TNA are linked to the amplitude and persistence of El Niño/La Niña events regardless of the horizontal resolution of the model. A note of caution is that the initial SST anomalies generated by El Niño and La Niña events over the TNA, those required to trigger the WES feedback, are linked to the ENSOrelated signal on the Canary Upwelling System in late winter. This result highlights the importance of properly reproducing the ENSO impact on the coastal upwelling off the African coast for a correct subsequent development of SST anomalies along the TNA in spring. In this context, the horizontal resolution of models is relevant since the aforementioned role of coastal upwelling is stronger in HR models than in LR models. This result is sustained by the thinner and more realistic representation of the mixed layer depth in HR models, which enhances the coupling between the ENSO-related winds and coastal upwelling. A similar improvement of the oceanic stratification with a high-resolution CGCM, and a related influence on the wind-induced upwelling, have been documented in the past for the nearby open-ocean upwelling known as the Guinea Dome (Doi et al. 2012).

The relevance of the mixed layer depth in our study region goes beyond better understanding the ENSO-TNA teleconnection in models. For instance, as the multidecadal variability of the Atlantic (AMV) can drive changes in the mixed layer depth, our results raise the question of how this teleconnection might be affected by the AMV in observational analyses. Thus, could the AMV alter the mixed layer depth in such a way that the role of coastal upwelling on the ENSO-TNA teleconnection was enhanced in some decades and weakened in others? This would be coherent with a recent analysis pointing to a variation of the ENSO-TNA teleconnection at decadal time scales according to the AMV phase (Park and Li 2019). A remaining subject for future studies will therefore be to analyze whether positive and negative AMV phases could lead to distinct couplings between the ENSO-related winds and the coastal upwelling off northwest Africa in a similar way as found here for LR and HR models. In addition, it is necessary to note that other factors, apart from the local mixed layer depth suggested here, could be contributing to modulate the ENSOTNA teleconnection in climate models and in observations. Notable among them are the strength, timing and diversity of ENSO (Lee et al. 2008; Rodrigues et al. 2011; Taschetto et al. 2016), or the zonal mean flow at upper troposphere (LópezParages et al. 2014, 2016). Thus, more careful investigation regarding the relative contributions of all these factors should necessarily be further analyzed in future works, which probably will require the addition of model sensitivity experiments.

It is worth also mentioning that four out of six models analyzed here include increased nominal resolution (i.e., HR model versions) in both the ocean and the atmosphere. Just in the case of MPI-M and CMCC the increased resolution is constrained to the atmospheric model (see Table 1). At first sight, the differences in the ENSO-TNA teleconnection among LR and HR versions identified here for these two models does not seem to be significantly lower than those found for the rest of models. However, a deeper analysis would be needed in future works in order to disentangle the relative contributions associated with the atmospheric and the oceanic component of the CGCM.

A clear conclusion to be drawn from the presented results is that the choice of a model (or a sample of models in ensemble analyses) affects the scope of the ENSO impact on the TNA. As revealed here, this choice may lead to significantly underestimate or overestimate the predictability of the TNA response to ENSO. This issue should be taken into account in future analyses before making categorical statements regarding this teleconnection.

Acknowledgments. This work was mainly funded by the European PRIMAVERA project (641727, Process-Based Climate Simulation: Advances in High Resolution Modelling and European Climate Risk Assessment; https://www.primavera-h2020.eu/). It has been also part of the IS-ENES3 project that has received funding from the European Union's Horizon 2020 research and innovation programme under Grant Agreement 824084. Authors also thank the colleagues within the TROPA-UCM group (http://tropa.fis.ucm.es/) and the climate group of CERFACS (https://cerfacs.fr/en/climate-variability-and-predictability/) for their interesting discussions and feedback.

\section{REFERENCES}

Chang, P., Y. Fang, R. Saravanan, L. Ji, and H. Seidel, 2006: The cause of the fragile relationship between the Pacific El Niño and the Atlantic Niño. Nature, 443, 324-328, https://doi.org/ 10.1038/nature 05053 .

Cherchi, A., and Coauthors, 2019: Global mean climate and main patterns of variability in the CMCC-CM2 coupled model. J. Adv. Model. Earth Syst., 11, 185-209, https://doi.org/ 10.1029/2018MS001369.

Chiang, J. C., and D. J. Vimont, 2004: Analogous Pacific and Atlantic meridional modes of tropical atmosphere-ocean variability. J. Climate, 17, 4143-4158, https://doi.org/10.1175/ JCLI4953.1. 
Czaja, A., P. van der Vaart, and J. Marshall, 2002: A diagnostic study of the role of remote forcing in tropical Atlantic variability. J. Climate, 15, 3280-3290, https://doi.org/10.1175/15200442(2002)015<3280:ADSOTR > 2.0.CO;2.

Doi, T., G. A. Vecchi, A. J. Rosati, and T. L. Delworth, 2012: Biases in the Atlantic ITCZ in seasonal-interannual variations for a coarse- and a high-resolution coupled climate model. J. Climate, 25, 5494-5511, https://doi.org/10.1175/JCLI-D-1100360.1 .

Enfield, D. B., and D. A. Mayer, 1997: Tropical Atlantic sea surface temperature variability and its relation to El Niño-Southern Oscillation. J. Geophys. Res., 102, 929-945, https://doi.org/ 10.1029/96JC03296.

Folland, C. K., T. N. Palmer, and D. E. Parker, 1986: Sahel rainfall and worldwide sea temperatures, 1901-85. Nature, 320, 602607, https://doi.org/10.1038/320602a0.

García-Serrano, J., C. Cassou, H. Douville, A. Giannini, and F. J. Doblas-Reyes, 2017: Revisiting the ENSO teleconnection to the tropical North Atlantic. J. Climate, 30, 6945-6957, https:// doi.org/10.1175/JCLI-D-16-0641.1.

Grossmann, I., and P. J. Klotzbach, 2009: A review of North Atlantic modes of natural variability and their driving mechanisms. J. Geophys. Res., 114, D24107, https://doi.org/10.1029/ 2009JD012728.

Gutjahr, O., D. Putrasahan, K. Lohmann, J. H. Jungclaus, J. S. von Storch, N. Brüggemann, H. Haak, and A. Stössel, 2019: Max Planck Institute Earth System Model (MPI-ESM1.2) for HighResolution Model Intercomparison Project (HighResMIP). Geophys. Model Dev., 12, 3241-3281, https://doi.org/10.5194/ gmd-12-3241-2019.

Haarsma, R. J., and Coauthors, 2016: High Resolution Model Intercomparison Project (HighResMIP v1.0) for CMIP6. Geosci. Model Dev., 9, 4185-4208, https://doi.org/10.5194/ gmd-9-4185-2016.

— , and Coauthors, 2020: HighResMIP versions of EC-Earth: EC-Earth3P and Ec-Earth3P-HR-Description, model computational performance and basic validation. Geosci. Model Dev., 13, 3507-3527, https://doi.org/10.5194/gmd-13-35072020.

Hastenrath, S., and L. Heller, 1977: Dynamics of climatic hazards in Northeast Brazil. Quart. J. Roy. Meteor. Soc., 103, 77-92, https://doi.org/10.1002/qj.49710343505.

Lee, S.-K., D. B. Enfield, and C. Wang, 2008: Why do some El Niños have no impact on tropical North Atlantic SST? Geophys. Res. Lett., 35, L16705, https://doi.org/10.1029/ 2008 GL034734.

López-Parages, J., B. Rodríguez-Fonseca, and L. Terray, 2014: A mechanism for the multidecadal modulation of ENSO teleconnection with Europe. Climate Dyn., 45, 867-880, https:// doi.org/10.1007/s00382-014-2319-x.

- _ _ E. Mohino, and T. Losada, 2016: Multidecadal modulation of ENSO teleconnection with Europe in late winter: Analysis of CMIP5 models. J. Climate, 29, 8067-8081, https:// doi.org/10.1175/JCLI-D-15-0596.1.
Nobre, P., and J. Shukla, 1996: Variations of sea surface temperature, wind stress, and rainfall over the tropical Atlantic and South America. J. Climate, 9, 2464-2479, https://doi.org/ 10.1175/1520-0442(1996)009<2464:VOSSTW >2.0.CO;2.

Oettli, P., Y. Morioka, and T. Yamagata, 2016: A regional climate mode discovered in the North Atlantic: Dakar Niño/Niña. Sci. Rep., 6, 18782, https://doi.org/10.1038/srep18782.

Park, J.-H., and T. Li, 2019: Interdecadal modulation of El Niñotropical North Atlantic teleconnection by the Atlantic multidecadal oscillation. Climate Dyn., 52, 5345-5360, https:// doi.org/10.1007/s00382-018-4452-4.

Roberts, C. D., R. Senan, F. Molteni, S. Boussetta, M. Mayer, and S. P. Keeley, 2018: Climate model configurations of the ECMWF Integrated Forecasting System (ECMWF-IFS cycle 43r1) for HighResMIP. Geosci. Model Dev., 11, 3681-3712, https://doi.org/10.5194/gmd-11-3681-2018.

Roberts, M., 2019: CMIP6 HighResMIP: Tropical storm tracks as calculated by the TempestExtremes algorithm. Centre for Environmental Data Analysis, accessed 2 September 2019, https:// catalogue.ceda.ac.uk/uuid/438268b75fed4f27988dc02f8a1d756d.

Rodrigues, R. R., R. J. Haarsma, E. J. Campos, and T. Ambrizzi, 2011: The impacts of inter-El Niño variability on the tropical Atlantic and Northeast Brazil climate. J. Climate, 24, 34023422, https://doi.org/10.1175/2011JCLI3983.1.

Roy, C., and C. Reason, 2001: ENSO related modulation of coastal upwelling in the eastern Atlantic. Prog. Oceanogr., 49, 245255, https://doi.org/10.1016/S0079-6611(01)00025-8.

Taschetto, A. S., R. Rodrigues, G. Meehl, S. McGregor, and M. England, 2016: How sensitive are the Pacific-tropical North Atlantic teleconnections to the position and intensity of El Niño-related warming? Climate Dyn., 46, 1841-1860, https://doi.org/10.1007/s00382-015-2679-x.

, C. C. Ummenhofer, M. F. Stuecker, D. Dommenget, K. Ashok, R. R. Rodrigues, and S.-W. Yeh, 2020: Enso atmospheric teleconnections. El Niño Southern Oscillation in a Changing Climate, Wiley, 309-335.

Vimont, D. J., and J. P. Kossin, 2007: The Atlantic meridional mode and hurricane activity. Geophys. Res. Lett., 34, L07709, https://doi.org/10.1029/2007GL029683.

Voldoire, A., and Coauthors, 2019: Evaluation of CMIP6 deck experiments with CNRM-CM6-1. J. Adv. Model. Earth Syst., 11, 2177-2213, https://doi.org/10.1029/2019MS001683.

Wang, C., 2004: ENSO, Atlantic climate variability, and the Walker and Hadley circulations. The Hadley Circulation: Present, Past and Future, Springer, 173-202.

Xie, S.-P., and S. G. H. Philander, 1994: A coupled ocean-atmosphere model of relevance to the ITCZ in the eastern Pacific. Tellus, 46A, 340-350, https://doi.org/10.3402/tellusa.v46i4.15484.

, and J. A. Carton, 2004: Tropical Atlantic variability: Patterns, mechanisms, and impacts. Earth's Climate: The Ocean-Atmosphere Interaction, Geophys. Monogr., Vol. 147, Amer. Geophys. Union, 121-142.

Zebiak, S. E., 1993: Air-sea interaction in the equatorial Atlantic region. J. Climate, 6, 1567-1586, https://doi.org/10.1175/15200442(1993)006<1567:AIITEA > 2.0.CO;2. 